\title{
In Vivo Evidence for Alcohol-Induced Neurochemical Changes in Rat Brain Without Protracted Withdrawal, Pronounced Thiamine Deficiency, or Severe Liver Damage
}

\author{
Natalie M Zahr ${ }^{1,2}$, Dirk Mayer²,3, Shara Vinco², Juan Orduna ${ }^{2}$, Richard Luong ${ }^{4}$, Edith V Sullivan*,1 and \\ Adolf Pfefferbaum ${ }^{1,2}$ \\ 'Psychiatry and Behavioral Sciences, Stanford University School of Medicine, Stanford, CA, USA; ${ }^{2}$ Neuroscience Program, SRI International, Menlo \\ Park, CA, USA; ${ }^{3}$ Radiology Department, Lucas MRS/I Center, Stanford University, Stanford, CA, USA; ${ }^{4}$ Department of Comparative Medicine, \\ Stanford University School of Medicine, Stanford, CA, USA
}

\begin{abstract}
Magnetic resonance spectroscopy (MRS) studies in human alcoholics report decreases in N-acetylaspartate (NAA) and cholinecontaining (Cho) compounds. Whether alterations in brain metabolite levels are attributable to alcohol per se or to physiological effects of protracted withdrawal or impaired nutritional or liver status remains unclear. Longitudinal effects of alcohol on brain metabolites measured in basal ganglia with single-voxel MRS were investigated in sibling pairs of wild-type Wistar rats, with one rat per pair exposed to escalating doses of vaporized alcohol, the other to vapor chamber air. MRS was conducted before alcohol exposure and twice during exposure. After 16 weeks of alcohol exposure, rats achieved average blood alcohol levels (BALs) of $\sim 293 \mathrm{mg}$ per $100 \mathrm{ml}$ and had higher Cho and a trend for higher glutamine + glutamate (Glx) than controls. After 24 weeks of alcohol exposure, BALs rose to $\sim 445 \mathrm{mg}$ per $100 \mathrm{ml}$, and alcohol-exposed rats had higher Cho, Glx, and glutamate than controls. Thiamine and thiamine monophosphate levels were significantly lower in the alcohol than the control group but did not reach levels low enough to be considered clinically relevant. Histologically, livers of alcohol-exposed rats exhibited greater steatosis and lower glycogenosis than controls, but were not cirrhotic. This study demonstrates a specific pattern of neurobiochemical changes suggesting excessive membrane turnover or inflammation, indicated by high Cho, and alterations to glutamate homeostasis in the rat brain in response to extended vaporized alcohol exposure. Thus, we provide novel in vivo evidence for alcohol exposure as causing changes in brain chemistry in the absence of protracted withdrawal, pronounced thiamine deficiency, or severe liver damage.

Neuropsychopharmacology (2009) 34, I427-1442; doi:I0.1038/npp.2008.I 19; published online 13 August 2008
\end{abstract}

Keywords: rat; magnetic resonance spectroscopy; vaporized alcohol; alcoholism; thiamine; liver

\section{INTRODUCTION}

In vivo magnetic resonance spectroscopy (MRS) provides a noninvasive method for the identification, visualization, and quantification of specific brain biochemical markers and neurotransmitters reflecting molecular processes. MRS thus enables the direct in vivo assessment of the neurochemical status of discrete brain structures with the potential of identifying mechanisms underlying selective brain pathologies and their evolution, including those induced by chronic alcoholism. In general, the study of chronic alcoholism in the human condition is hampered by the heterogeneity of alcoholic populations examined with respect to length of sobriety, pattern of drinking, and

*Correspondence: Dr EV Sullivan, Psychiatry and Behavioral Sciences, Stanford University School of Medicine, 40I Quarry Road, Stanford, CA 94305-5723, USA, Tel: + I 650859 2880, Fax: + I 6508592743 , E-mail: edie@stanford.edu

Received 15 April 2008; revised 8 July 2008; accepted I3 July 2008 frequency of withdrawals. Further, seldom is the nutritional or hepatic status of human alcoholics considered in MRS studies of alcoholism, leaving ambiguity as to whether the genesis of brain metabolite differences is the result of withdrawal, nutritional status, or alcohol per se. In contrast with the often-indeterminable natural course of alcohol use in humans, animal models allow for the determination of alcohol toxicity controlled for multiple factors.

The predominant MRS signal in the healthy human brain is $\mathrm{N}$-acetylaspartate (NAA), found almost exclusively in neurons (Petroff et al, 1995; Urenjak et al, 1992) and thus considered a marker of neuronal integrity. Choline-containing (Cho) compounds, including free Cho, phosphocholine, and glycerophosphocholine, are associated with cell membrane synthesis, turnover, and metabolism (Stoll et al, 1995). Other prominent and often-reported signals include myo-inositol (mI), described as a glial marker (Brand et al, 1993; Petroff et al, 1995) or intracellular osmolyte (Ernst et al, 1997; Lien et al, 1990), creatine (Cr), influenced by the 
state of high-energy phosphate metabolism (Tedeschi et al, 1995), and a signal with combined contributions from glutamine + glutamate (Glx). Recently, advanced MRS methods have allowed for the isolation of the glutamate (Glu) signal, the principal excitatory neurotransmitter of the brain (Mayer and Spielman, 2005b).

Studies of recently detoxified alcoholics (within 30 days of detoxification) show abnormally low levels of NAA, inferred from ratios to total $\mathrm{Cr}(\mathrm{tCr})$ or amount of underlying tissue in frontal white matter (Meyerhoff et al, 2004; Schweinsburg et al, 2001, 2003), frontal gray matter (Bendszus et al, 2001; Durazzo et al, 2004; Jagannathan et al, 1996), thalamus (Jagannathan et al, 1996; Murata et al, 2001), and cerebellum (Bendszus et al, 2001; Jagannathan et al, 1996; Murata et al, 2001; Parks et al, 2002, but see O'Neill et al, 2001; Seitz et al, 1999). Likewise, Cho, whether expressed as a ratio to $\mathrm{tCr}$ or tissue water, is lower in recently detoxified alcoholics than controls in thalamus (Durazzo et al, 2004; Murata et al, 2001), and cerebellum (Bendszus et al, 2001; Jagannathan et al, 1996; Murata et al, 2001; but see O'Neill et al, 2001; Parks et al, 2002; Seitz et al, 1999).

A potential concomitant of chronic alcoholism is thiamine deficiency. Lower levels of both NAA and Cho compared with controls are reported in MRS case studies of thiamine deficiency (Wernicke's encephalopathy; Mascalchi et al, 2002; Murata et al, 2001) and models of severe thiamine deficiency in rats treated with pyrithiamine hydrochloride (Lee et al, 1995, 2001; Pfefferbaum et al, 2007; Rose et al, 1993). The MRS pattern of reduced NAA and Cho shared by recovering alcoholics and also humans and rats with thiamine deficiency questions the relative importance of alcohol $v s$ thiamine status in the genesis of MRS observable brain alterations.
Of individuals with alcoholism 10-15\% also develop cirrhosis of the liver (Anand, 1999), and of those, 67\% can develop hepatic encephalopathy (Prasad et al, 2007). A reduction in Cho is a key element in the MRS pattern distinguishing cirrhosis of the liver. Indeed, lower Cho and $\mathrm{mI}$, and higher Glx, with no change in NAA characterize the neurospectroscopic abnormalities consistently reported in the brains of cirrhotic patients (Cordoba et al, 2001; Geissler et al, 1997; Kreis et al, 1992; Laubenberger et al, 1997; Lee et al, 1999; Ross et al, 1994). Hepatic encephalopathy is associated with greater abnormalities in these metabolites (Cordoba et al, 2002).

In actively drinking, long-term alcohol-dependent humans and also in rodents exposed to $20 \%$ alcohol as the only source of fluid for 60 weeks, the pattern of MRS-detectable changes is different from that noted in alcoholics sober for at least 1 month. NAA (relative to tissue water) is only $5 \%$ lower in heavy-drinking compared with light-drinking humans in frontal white matter (Meyerhoff et al, 2004). And in contrast to the frequent observation in recovering, abstinent alcoholics, the levels of Cho are higher in parietal gray matter of actively drinking humans (Meyerhoff et al, 2004) and in the thalamus of rodents between weeks 16 and 40 of alcohol exposure (Lee et al, 2003). In the rodent study, Glx was also elevated in alcohol-exposed rats relative to controls (Lee et al, 2003); the human study did not measure Glx. Table 1 presents the neurospectroscopic patterns identified in each of these alcohol and alcohol-related conditions.

In the present study, we used a rodent alcohol inhalation system (La Jolla Alcohol Research Inc., La Jolla, CA) to expose rats to escalating doses of vaporized alcohol to test the hypothesis that alcohol, per se, would cause significant metabolite changes in the basal ganglia of wild-type male Wistar rats. We studied the basal ganglia because of

Table I Metabolite Levels by Disease

\begin{tabular}{|c|c|c|c|c|c|c|}
\hline Disease & NAA & Glu & Cho & $\mathbf{m l}$ & Glx & References \\
\hline \multicolumn{7}{|l|}{ Alcohol } \\
\hline Human (currently drinking) & & & $\uparrow$ & & & Meyerhoff et al (2004) \\
\hline Rat ( I 6-40 weeks) & & & $\uparrow$ & & $\uparrow$ & Lee et al (2003) \\
\hline \multicolumn{7}{|l|}{ Alcohol } \\
\hline Human (detoxified/recovering) & $\downarrow$ & & $\downarrow$ & $\uparrow$ & & $\begin{array}{l}\text { Schweinsburg et al (200I); Schweinsburg et al (2003); Bendszus et al (200I); } \\
\text { Jagannathan et al (1996); Durazzo et al (2004); Jagannathan et al (1996); Murata et al (200I); } \\
\text { Bendszus et al (200I); Jagannathan et al (1996); Murata et al (200I); Seitz et al (1999); } \\
\text { Parks et al (2002) }\end{array}$ \\
\hline Rat (> 40 weeks) & & & $\downarrow$ & & $\uparrow$ & Lee et al (2003) \\
\hline \multicolumn{7}{|l|}{ Thiamine deficiency } \\
\hline Human (Wernicke's) & $\downarrow$ & & $\downarrow$ & & & Murata et al (200I); Mascalchi et al (2002) \\
\hline Rat (pyrithiamine) & $\downarrow$ & & $\downarrow$ & & & Rose et al (1993); Pfefferbaum et al (2007); Lee et al (200 I); Lee et al (I995) \\
\hline \multicolumn{7}{|l|}{ Liver disease } \\
\hline Human (cirrhosis) & & & $\downarrow$ & $\downarrow$ & $\uparrow$ & $\begin{array}{l}\text { Lee et al (1999); Kreis et al (1992); Ross et al (1994); Geissler et al (1997); } \\
\text { Cordoba et al (200I); Laubenberger et al (1997) }\end{array}$ \\
\hline Rat (tetrachloride/thioacetamide) & & $\downarrow$ & $\downarrow$ & & $\uparrow$ & Bates et al (1989); Peeling et al (1993) \\
\hline
\end{tabular}

Abbreviations: NAA, N-acetylaspartate; Glu, glutamate; Cho, choline; ml, myo-inositol; Glx, glutamine+glutamate. 
evidence for its involvement in the loss of control over alcohol consumption (Modell et al, 1990; Tabakoff, 1979; Xia et al, 2006) and because of evidence that Glu in the basal ganglia may contribute to the neuropathology associated with alcoholism (Rossetti et al, 1999; Ulrichsen et al, 1996). The expectation was that, in the absence of severe alcohol withdrawal phenomena, pronounced thiamine deficiency, or severe liver dysfunction, the pattern of metabolite changes would differ from that in abstinent, recovering human alcoholics, and more likely resemble the active drinkers and reveal increases, rather than decreases in Cho, and elevations in Glu and Glx.

\section{MATERIALS AND METHODS}

\section{Subjects}

The study group comprised 10 sibling pairs of healthy, male, wild-type Wistar rats (Charles River Laboratories) weighing $292.8 \pm 38.0 \mathrm{~g}$ at the time of reception (56 days old). Rats were singly housed with free access to food and water, acclimated to a reversed 14-h light/10-h dark cycle (ie lights on at 1900 to 0900 hours for the rats' sleep cycle), and weighed once per week for 14 weeks before the first imaging session (MRS 1). The Institutional Animal Care and Use Committees at SRI International and Stanford University approved all procedures. This same group of rats underwent structural MRI examination (Pfefferbaum et al, 2008).

\section{Alcohol Exposure}

After the first imaging session (MRS 1, pre-alcohol baseline scanning), one rat from each sibling pair was exposed to a mixture of alcohol and oxygen (alcohol weight: $625.88 \pm 97.41 \mathrm{~g}$ ), the other to oxygen (control weight: $629 \pm 76.88 \mathrm{~g}, p=0.94)$, using a rodent alcohol inhalation system (La Jolla Alcohol Research Inc.). Rats were exposed to vaporized alcohol for a total of 24 weeks; MRS was performed at week 16 (MRS 2) and week 24 (MRS 3). Ethanol vapor was created by dripping $95 \%$ alcohol into a $4000 \mathrm{ml}$ Erlenmeyer vacuum flask kept at $50^{\circ} \mathrm{C}$ on a warming tray. Air was blown over the bottom of the flask at $11 \mathrm{l} / \mathrm{min}$ to vaporize alcohol. Concentrations of alcohol vapor were adjusted by varying the rate at which alcohol was pumped into the flask and ranged from 15 to $30 \mathrm{mg} / \mathrm{l}$. Chambers administering intermittent vapor were connected to a timer that would turn the chambers on and off every day so that animals received alcohol vapor for $14 \mathrm{~h}$ at night during their sleep cycle (ie starting at 1900 hours). Previous work has demonstrated that alcohol vapor exposure is a reliable technique: animals are free to move and blood alcohol levels (BALs) can be maintained at specific levels (Roberts et al, 2000). Tail blood ( $\sim 0.5 \mathrm{ml})$ sampled for BAL determination was collected into heparinized Eppendorf tubes. After centrifugation, the plasma was extracted and assayed for alcohol content based on direct reaction with the enzyme alcohol oxidase (Analox Instruments Ltd., UK).

\section{MRS Acquisition}

We employed an imaging method previously described (Mayer et al, 2007a). Briefly, animals were held in an
MR-invisible structure, which provided support for the radiofrequency coil and a nose cone for the delivery of isoflurane anesthesia (2-3.5\%) and oxygen (1.5 1/min). Rectal temperature and oxygen saturation from the hindlimb were monitored throughout the experiment. Heating was provided by prewarmed bags of saline solution placed under the animal tray. Rats were scanned in sessions of $\sim 2 \mathrm{~h}$ each.

Proton MR spectra were acquired on a clinical $3 \mathrm{~T}$ GE human scanner equipped with a high-strength insert gradient coil (Adalsteinsson et al, 2004). Coronal fast spin-echo images (echo time (TE)1/TE2/repetition time $(\mathrm{TR})=12.0 / 62.6 / 3000 \mathrm{~ms}$, field of view $=8 \times 4 \mathrm{~cm}^{2}$, $256 \times 128,1 \mathrm{~mm}$ thick) were used to prescribe an approximately $0.25 \mathrm{~mm}^{3}$ brain voxel $\left(10 \times 5 \times 5 \mathrm{~mm}^{3}\right)$ in the basal ganglia. The voxel was placed approximately $2.5 \mathrm{~mm}$ anterior and posterior to bregma, $5 \mathrm{~mm}$ to the right and left of midline, and $5 \mathrm{~mm}$ inferior to $\sim-3.10 \mathrm{~mm}$ bregma, according to the atlas of Paxinos and Watson (2005) (Figure 1).

Spectroscopy was performed with a constant time point resolved spectroscopy (CT-PRESS) sequence (Mayer and Spielman, 2005a; Mayer et al, 2007b) consisting of modified PRESS module in which the position of the last refocusing pulse was shifted to encode the chemical shift (CS) in the second time dimension $\left(t_{1}\right)$. The pulse was shifted in 129 steps with an increment $\Delta t_{1} / 2=0.8 \mathrm{~ms}$ corresponding to a spectral width $\left(\mathrm{SW}_{1}\right)$ of $625 \mathrm{~Hz}$ in $f_{1}$. The average TE of the sequence was $139 \mathrm{~ms}$ optimized for the detection of Glu. To increase signal-to-noise ratio, data acquisition (2048 complex points at $\mathrm{SW}_{2}=5000 \mathrm{~Hz}$ ) started immediately after the last crusher gradient of the second refocusing pulse. CTPRESS was preceded by a three-pulse CS-selective sequence for water suppression and an outer volume suppression module using selective saturation pulses. TR was $2 \mathrm{~s}$ and four excitations were performed without data acquisition to establish a steady state. With six averages, the acquisition time per spectrum was $26: 36 \mathrm{~min}$. An additional acquisition without water suppression was carried out (17 CS encoding steps, $\Delta t_{1} / 2=6.4 \mathrm{~ms}$, two averages, $\left.T_{\mathrm{acq}}=1: 16 \mathrm{~min}\right)$ to measure tissue water content used to normalize the metabolite signal intensities.

The amount of cerebral spinal fluid and tissue water was estimated by fitting the data acquired without water suppression across the 17 TEs to a biexponential model, as described in Mayer et al (2007b). Apodization of the water-suppressed data involved multiplication with sinebell functions in both time dimensions and zero filling up to $4096 \times 1024$ data points. A $t_{1}$-dependent shift was applied in $t_{2}$ correcting for the different start of data acquisition. After performing a two-dimensional fast Fourier transform, effectively decoupled one-dimensional CT-PRESS spectra were obtained by integrating the signal along $f_{2}$ within a $\pm 13 \mathrm{~Hz}$ interval around the spectral diagonal. Metabolite signals in the one-dimensional spectra were evaluated by peak integration with an interval of $\pm 6 \mathrm{~Hz}$. The quality of the spectra allowed evaluation of signals from NAA (2.02 p.p.m.), tCr (3.03 and 3.93 p.p.m.), Cho (3.24 p.p.m.), Glu (2.36 p.p.m.), Glx (3.78 p.p.m.), mI (3.58 p.p.m.), and taurine (Tau, 3.44 p.p.m.). For comparison with published data, metabolite results were also analyzed using $\mathrm{tCr}$ as the referent. 

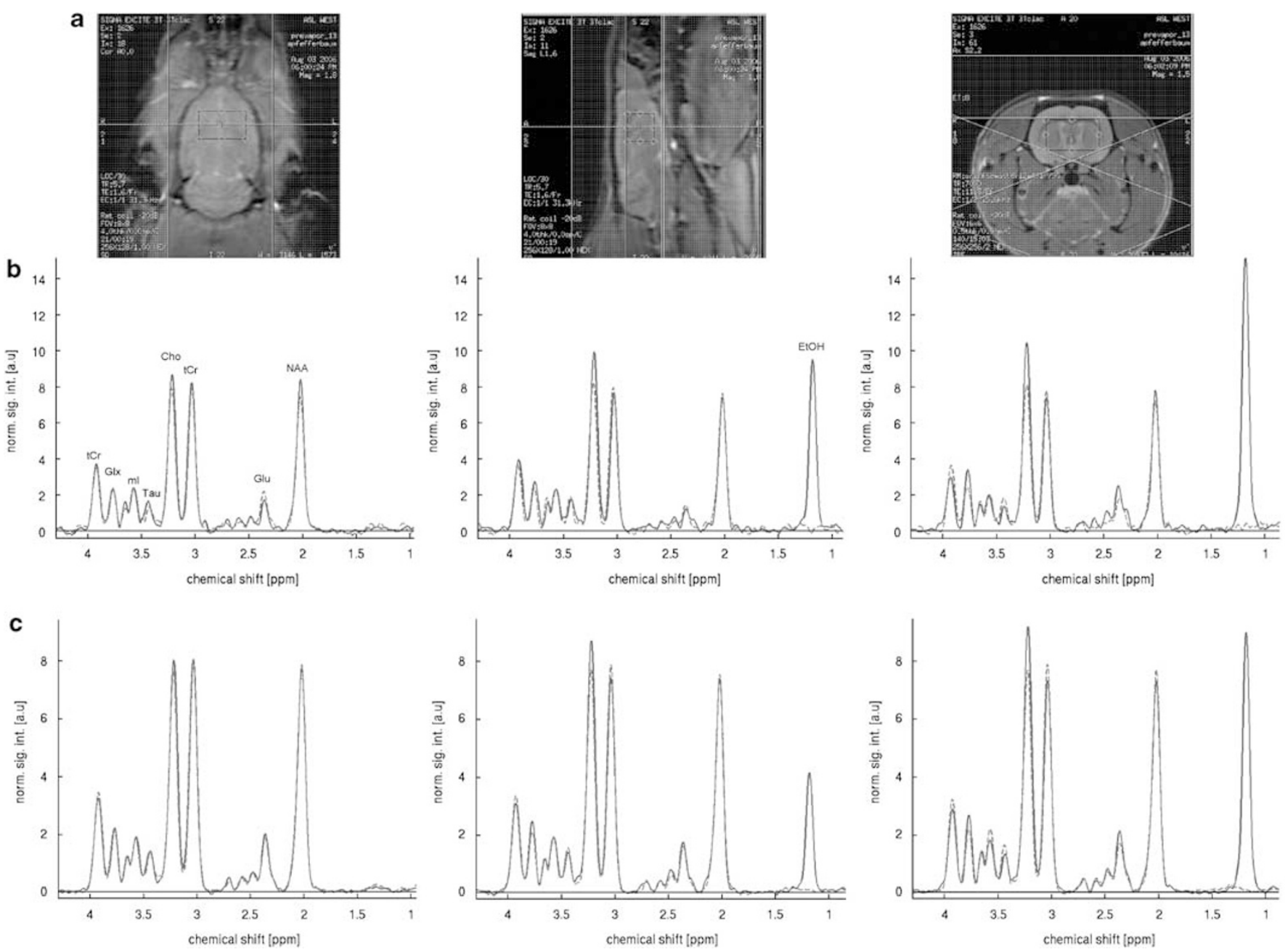

Figure I (a) Voxel location in axial, sagittal, and coronal planes. (b) Sample spectra from a control (red) and alcohol-exposed (blue) rat at baseline, after 16 weeks, and 24 weeks of alcohol exposure. (c) Average signal intensity of metabolites relative to tissue water, at baseline, 16 weeks, and 24 weeks alcohol exposure ( $n$ (control, red) $=10, n$ (alcohol, blue) $=8)$.

\section{Behavioral Analysis}

Before MRS 1, all rats were trained to criterion of achieving perfect performance in maintaining balance on a rotarod (6 r.p.m., $45 \mathrm{~s}$, two consecutive trials). Performance was tested before MRS 2 (16 weeks alcohol) and MRS 3 (a total of 24 weeks alcohol). Neurological examination based on established guidelines (Becker, 2000; Pitkin and Savage, 2001) was performed before MRS 2 and MRS 3, in the morning, within $1-2 \mathrm{~h}$ of alcohol exposure, and in the evening, within $8-10 \mathrm{~h}$ of alcohol exposure. Rats were rated $(0=$ absent, $1=$ present $)$ for neurological signs including autonomic, sensory, and motor functions.

\section{Thiamine Assay}

After MRS 3, plasma was collected from 17 rats (7 alcohol, an additional alcohol rat died unexpectedly after MRS 3; 10 control), frozen, and sent to the Stanford University Mass Spectrometry Laboratory where it was analyzed for concentrations of thiamine, thiamine monophosphate (TMP) and thiamine pyrophosphate (TPP, also known as thiamine diphosphate). Samples $(100 \mu \mathrm{l}$ aliquots) were thawed and spiked with $50 \mathrm{pmol}$ reserpine (used as an internal standard). Protein precipitation in cold, acidic $(0.1 \%$ formic acid) acetonitrile was performed. The samples were centrifuged and the supernatant was recovered, dried, and resuspended in $30 \mathrm{mM}$ ammonium formate $(\mathrm{pH} 3)$. Ten $\mu l$ of the sample was injected into the high-performance liquid chromatography-mass spectrometer (LC-MS) system. Samples were analyzed in duplicate. High-performance liquid chromatography (HPLC) separation of thiamine and its phosphates was achieved on an Atlantis T3 column (C18, $100 \times 2.1 \mathrm{~mm}, 3 \mu \mathrm{m}, 100 \AA$; Waters Corp., Milford, MA) using an Agilent 1100HPLC system equipped with degasser and autosampler (Agilent, Santa Clara, CA). Flow rate was $0.2 \mathrm{ml} / \mathrm{min}$, mobile phase A was $30 \mathrm{mM}$ ammonium formate ( $\mathrm{pH} 3)$, and mobile phase $\mathrm{B}$ was acetonitrile. The analytes were separated with the linear gradient from 0 to $80 \%$ B in $2.8 \mathrm{~min}$. Total time of LC-MS analysis was $6 \mathrm{~min}$; retention times were as follows: thiamine $2.10 \mathrm{~min}$, TMP $1.96 \mathrm{~min}$, and TPP $1.80 \mathrm{~min}$. The Micromass Quattro Premier triple quadruple mass spectrometer (Waters Corp.) equipped with an electrospray source was used for detection of the HPLC eluent and selective quantitation of the analytes. MS data were acquired in single reaction monitoring mode 
where the analytes' unique precursor ion-fragment ion transitions were monitored: thiamine $265.1>121.8$, TPP $345.1>121.8$, and TMP $425.1>121.8$. Cone voltage depended on the analyte $(20-25 \mathrm{~V})$, extractor voltage was $3 \mathrm{~V}$, source temperature was $120^{\circ} \mathrm{C}$, and vaporizer temperature was $350^{\circ} \mathrm{C}$. Collision energy also depended on the analyte $(16-20 \mathrm{eV})$. The limits of quantification were as follows: thiamine $0.05 \mathrm{fmol}$, TMP $2.0 \mathrm{fmol}$, and TPP $20 \mathrm{fmol}$ per injection in sample buffer. For data analysis, MassLynx and QuanLynx software (Waters Corp.) were employed.

\section{Liver Histopathology}

Left lateral lobe liver specimens from 17 rats (7 alcohol, 10 control) were quick-frozen by immersion in isopentane at $-160^{\circ} \mathrm{C}$. Samples were wrapped in foil, placed in falcon tubes, and stored at $-70^{\circ} \mathrm{C}$ until processing. For histopathology, frozen liver specimens were simultaneously thawed and fixed in $10 \%$ buffered formalin solution at room temperature for $48 \mathrm{~h}$. After fixation, the specimens were prepared with a standard hematoxylin and eosin stain and a Masson's Trichrome stain.

Cross-sectional areas of the left lateral lobe were morphologically assessed for hepatic pathologies. Specific pathologies evaluated included hepatic steatosis (intracellular accumulation of fat in hepatocytes), alcoholic hepatitis (hepatocellular swelling and/or necrosis, with or without a neutrophilic inflammatory reaction; presence of Mallory bodies; and presence of sinusoidal and/or portocentric fibrosis), and alcoholic cirrhosis (hepatocellular parenchymal loss with evidence of nodular hepatocellular regeneration; presence of bridging fibrosis; bile ductular proliferation; and presence of portocentric lymphoplasmacytic inflammation). The veterinary pathologist (RL) assessed liver specimens post-fixation only and blind to group. Morphological changes were graded on a $0-4$ scale, where $0=$ no pathology, $1=$ minimal (affects $<5 \%$ of tissue), $2=$ mild (affects $5-20 \%$ of tissue), $3=$ moderate (affects $20-50 \%$ of tissue), and $4=$ severe (affects $>50 \%$ of tissue).

\section{Statistical Analysis}

Group differences were tested with repeated-measures analysis of variance (ANOVA), Spearman's rank order tests corrected for ties, and paired $t$-tests, where appropriate. Alcohol effects were subject to one-tailed tests because our primary hypothesis was that alcohol exposure would result in no change in NAA, and higher levels of Cho, Glu, and Glx in the alcohol than control groups. All remaining comparisons were analyzed with two-tailed $t$-tests.

\section{RESULTS}

After the first 16 weeks of intermittent alcohol exposure (MRS 2), two rats died prematurely; the remaining eight rats in the alcohol group reached average BALs of $292.98 \pm 42.12 \mathrm{mg}$ per $100 \mathrm{ml}$ (range 240.5-385.6 mg per $100 \mathrm{ml}$ ) and lost $1.2 \%$ body weight (alcohol: $606 \pm 83.17 \mathrm{~g}$ ), whereas controls gained $13.4 \%$ of their baseline body weight (control: $713.69 \pm 93.97 \mathrm{~g}, p=0.02$ ). After 8 more weeks of alcohol exposure (MRS 3), the alcohol group achieved average BALs of $444.63 \pm 24.14 \mathrm{mg}$ per $100 \mathrm{ml}$ (range $324.3-$ $514.1 \mathrm{mg}$ per $100 \mathrm{ml}$ ) and weighed $567.1 \pm 107.58 \mathrm{~g}$ (lost $6.8 \%$ more of their body weight) whereas controls weighed $733.47 \pm 96.94 \mathrm{~g}$, having gained $2.9 \%$ more of their body weight since MRS $2(p=0.003)$.

\section{Metabolites}

For metabolite signals normalized to tissue water, a twogroup repeated-measures (three MRS sessions and seven metabolite signals) ANOVA revealed a significant group-bymetabolite-by-time interaction $(p=0.0002)$. Follow-up analysis of metabolites considered in our primary hypothesis identified significant effects of group or group-by-session interactions for Cho, Glx, and Glu. The groups did not differ at baseline, but after 16 weeks of alcohol exposure, the alcohol group had significantly higher Cho $(p=0.0002)$ levels than controls, and Glx $(p=0.05)$ showed a trend in the same direction. After 8 more weeks of greater alcohol exposure, the alcohol group had higher Cho $(p=0.001)$, Glx $(p=0.0035)$, and Glu $(p=0.0129)$ than the control group (Figures 1 and 2; Table 2). A family-wise Bonferroni correction for four metabolite signals examined with pairwise tests would require a one-tailed significance of $p \leqslant 0.025$, and a two-tailed significance of $p \leqslant 0.0125$. Thus, even with a two-tailed Bonferroni correction, the increase in Cho was significant at MRS 2, and increases in Cho, Glx, and Glu were significant at MRS 3.

Ratios relative to $\mathrm{tCr}$ yielded a similar pattern of alcohol effects as did ratios relative to water. In particular, a repeated-measures ANOVA revealed a significant group-bymetabolite-by-time interaction $(p=0.0001)$. Again, the groups did not differ at baseline, but after 16 weeks of alcohol exposure, the alcohol group had higher $\mathrm{Cho/tCr}$ $(p=0.0001), \mathrm{Glx} / \mathrm{tCr}(p=0.0155)$, and Glu/tCr $(p=0.0176)$ ratios, which persisted at 24 weeks of escalating alcohol exposure (Cho/tCr, $p=0.0001$; Glx/tCr, $p=0.0004$; Glu/tCr, $p=0.0027$; Table 2). The ratio values and patterns across the three time points were similar whether Cho was analyzed relative to $\mathrm{tCr}$ or to $\mathrm{NAA}$, ie in both cases, ratio differences across the three time points in controls were not significant, whereas Cho was higher in the alcohol group compared with controls at MRS 2 and MRS 3. In the alcohol group, Cho/tCr ratios demonstrated an increase across all times points such that MRS $1<$ MRS $2<$ MRS 3, and all three time comparisons were significant. Cho/NAA ratios followed the same pattern as $\mathrm{Cho/tCr}$ ratios; however, Cho/ NAA levels at MRS 3 were not significantly higher than those at MRS 2.

Analysis of the remaining metabolites using two-tailed $t$ tests revealed no significant differences between groups, except for an elevation in $\mathrm{mI}$ relative to tissue water in the control compared to the alcohol group at MRS 3 $(p=0.0216)$ that may be inaccurate because quantitation of $\mathrm{mI}$ in the presence of alcohol is hampered by spectral overlap with the methylene signal of ethanol at $3.6 \mathrm{ppm}$.

A final set of analyses took advantage of the sibling pair design (Figure 3), which can reduce variance but, in this case, also reduced power because for the two rats that died, both they and their sibling pairs had to be removed from the analysis. The results yielded a significant difference 

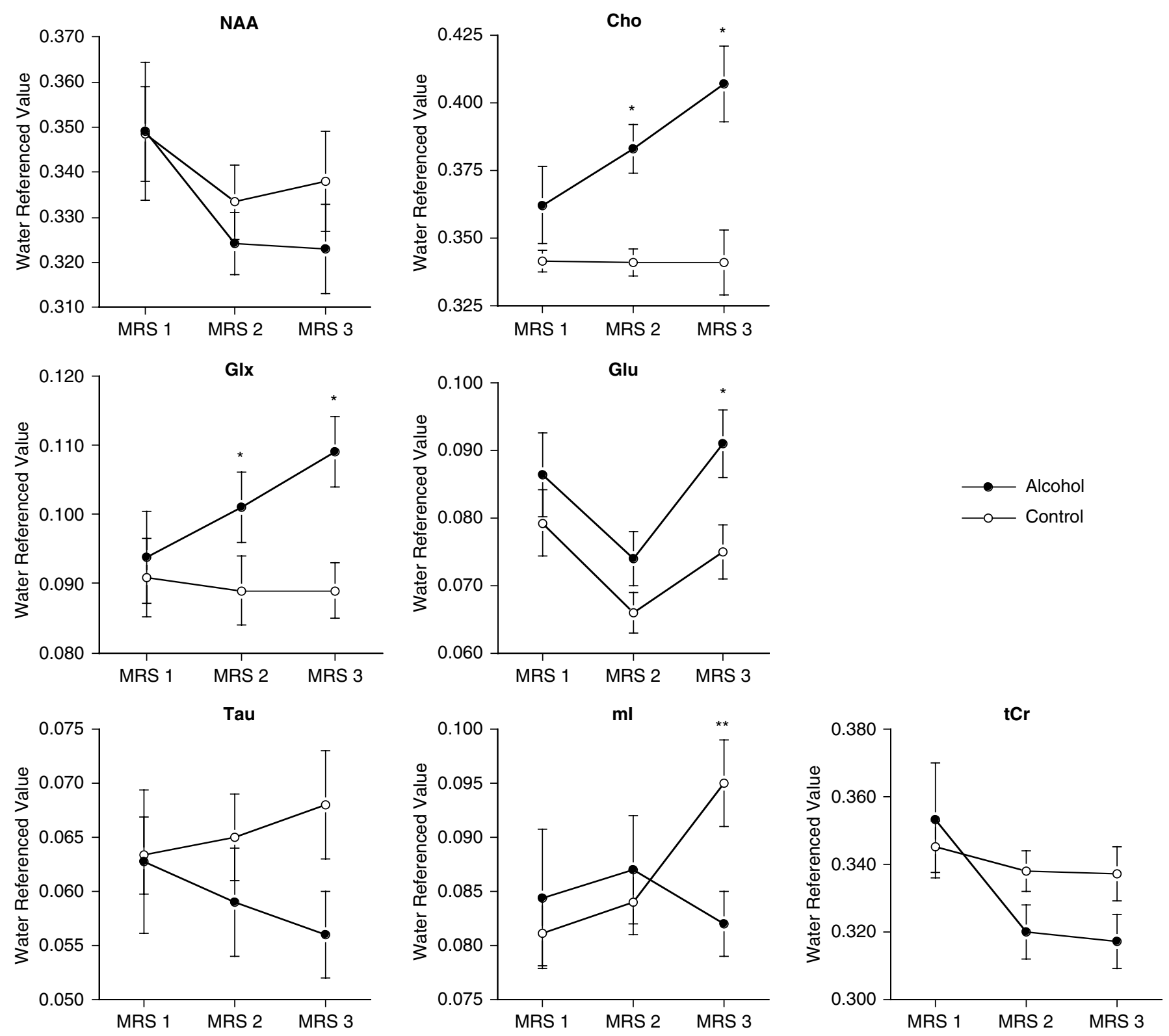

Figure 2 Mean \pm SEM of the 7 metabolite signals quantified relative to tissue water for each of the 3 MRS acquisitions for the control (open circles) and alcohol-exposed (closed circles) rats. ${ }^{*} p \leqslant 0.05$, I-tailed. ${ }^{*} p \leqslant 0.05,2$-tailed.

$(p \leqslant 0.05)$ in the Fisher's protected least-significant difference test for Glx between MRS 1 and MRS 3 only.

\section{Thiamine and Phosphate Derivatives}

Plasma assay for thiamine and its phosphate derivates demonstrated that thiamine $(p=0.0063)$ and TMP $(p=0.0377)$ levels were significantly lower in the alcohol group than controls (Table 3). A follow-up set of analyses taking advantage of the sibling pair design (Figure 3) confirmed the significant difference for thiamine $(p=0.02)$. The alcohol-exposed animals had thiamine and TMP levels approximately $30 \%$ below the level of the controls. Within the alcohol group, thiamine $(r=-0.86, \quad p=0.013$; $\rho=-0.96, p=0.0182)$ and TMP $(r=-0.97, p=0.0004$; $\rho=-0.82, p=0.0442$ ) levels correlated with BALs taken shortly before MRS 3, indicating the higher the BALs, the lower the thiamine and TMP levels (Figure 4). TMP levels also correlated with the difference in alcohol rat weights between MRS 2 and MRS 3, indicating the lower TMP levels, the more weight loss $(r=0.82, p=0.024 ; \rho=0.89$, $p=0.0287)$. Due to the death of two alcohol-exposed animals prior to the termination of the experiment, reduced statistical power mitigated against detecting significant correlations between thiamine levels and metabolite levels or neurological status. In the combined groups, Cho relative to tissue water at MRS 3 correlated with TMP $(r=-0.50$, $p=0.0427 ; \rho=-0.62, p=0.0124)$ and $\mathrm{Cho} / \mathrm{tCr}$ at MRS 3 correlated with thiamine $(r=-0.54, p=0.0245 ; \rho=-0.51$, $p=0.0414)$ and TMP $(r=-0.61, p=0.0089 ; \rho=-0.68$, $p=0.0062) ; \mathrm{Glu} / \mathrm{tCr}$ at MRS 3 correlated with TMP $(r=-0.47, p=0.0542 ; \rho=-0.55, p=0.0267)$. 
Table 2 Metabolite Levels in Basal Ganglia Voxel: Means and Standard Deviations

\begin{tabular}{|c|c|c|c|c|c|c|c|}
\hline & NAA & Cho & Glu & Glx & $\mathrm{tCr}$ & Tau & $\mathbf{m l}$ \\
\hline \multicolumn{8}{|l|}{ MRS I } \\
\hline \multicolumn{8}{|c|}{ Relative to tissue water } \\
\hline $\mathrm{EtOH}$ & $0.349 \pm 0.043$ & $0.362 \pm 0.040$ & $0.087 \pm 0.017$ & $0.094 \pm 0.019$ & $0.353 \pm 0.048$ & $0.063 \pm 0.019$ & $0.084 \pm 0.018$ \\
\hline Ctrl & $0.348 \pm 0.033$ & $0.341 \pm 0.013$ & $0.079 \pm 0.016$ & $0.091 \pm 0.018$ & $0.345 \pm 0.024$ & $0.063 \pm 0.011$ & $0.081 \pm 0.010$ \\
\hline $\mathrm{EtOH}$ & $0.989 \pm 0.027$ & $1.03 \pm 0.065$ & $0.245 \pm 0.036$ & $0.264 \pm 0.028$ & I & $0.179 \pm 0.058$ & $0.239 \pm 0.044$ \\
\hline Ctrl & $1.01 \pm 0.053$ & $0.993 \pm 0.05 \mid$ & $0.229 \pm 0.036$ & $0.262 \pm 0.043$ & I & $0.183 \pm 0.026$ & $0.236 \pm 0.026$ \\
\hline \multicolumn{8}{|l|}{ MRS 2} \\
\hline \multicolumn{8}{|c|}{ Relative to tissue water } \\
\hline \multicolumn{8}{|c|}{ Relative to $\mathrm{tCr}$} \\
\hline $\mathrm{EtOH}$ & $1.013 \pm 0.041$ & $1.199 \pm 0.098^{*}, \dagger$ & $0.231 \pm 0.034^{*}$ & $0.316 \pm 0.047^{*}, \dagger$ & । & $0.186 \pm 0.049$ & $0.273 \pm 0.046^{\dagger}$ \\
\hline Ctrl & $0.987 \pm 0.049$ & $|.01| \pm 0.05 \mid$ & $0.196 \pm 0.030^{\dagger}$ & $0.264 \pm 0.046$ & । & $0.192 \pm 0.040$ & $0.248 \pm 0.030$ \\
\hline \multicolumn{8}{|l|}{ MRS 3} \\
\hline \multicolumn{8}{|c|}{ Relative to tissue water } \\
\hline $\mathrm{EtOH}$ & $0.323 \pm 0.027$ & $0.407 \pm 0.040 * . \neq$ & $0.091 \pm 0.015^{*}$ & $0.109 \pm 0.015^{*}$ & $0.317 \pm 0.022$ & $0.056 \pm 0.012$ & $0.082 \pm 0.007 * * *$ \\
\hline Ctrl & $0.338 \pm 0.035$ & $0.34 I \pm 0.036$ & $0.075 \pm 0.013$ & $0.089 \pm 0.013$ & $0.337 \pm 0.025$ & $0.068 \pm 0.015$ & $0.095 \pm 0.013^{\ddagger}$ \\
\hline \multicolumn{8}{|c|}{ Relative to $\mathrm{tCr}$} \\
\hline $\mathrm{EtOH}$ & $1.019 \pm 0.054$ & $1.284 \pm 0.089 *, \ldots$ & $0.287 \pm\left. 0.04\right|^{*}, \#$ & $0.346 \pm 0.047^{*}, \neq$ & । & $0.177 \pm 0.029$ & $0.261 \pm 0.028$ \\
\hline
\end{tabular}

\section{Liver Histopathology}

None of the rats exhibited liver morphological changes consistent with moderate (grade 3) or severe (grade 4) pathology. Indeed, none of the rats exhibited morphological hepatic changes consistent with alcoholic cirrhosis as they lacked observable hepatocellular parenchymal loss, macroand micronodular hepatocellular regeneration, or bridging (centrilobular, portal-portal, and central-portal) fibrosis. Hepatocellular swelling and/or necrosis with neutrophilic inflammation (Figure 5a) is potentially indicative of alcoholic hepatitis. Minimal to mild hepatocellular swelling and necrosis were noted in four of seven alcohol-exposed rats, two of which also displayed accompanying neutrophilic inflammation. Two of ten control rats demonstrated minimal to mild hepatocellular swelling and necrosis with secondary neutrophilic inflammation. Sinusoidal fibrosis was absent, but minimal to mild portocentric fibrosis was observed in five of seven alcoholic and five of ten control rats. Mallory bodies were not detected. The groups did not differ significantly in the presence or severity of hepatocellular swelling, necrosis, inflammation, or portocentric fibrosis.

Hepatic steatosis ranged in severity from minimal to mild and was noted in all seven alcohol-exposed rats but only four of ten control rats. In the alcohol rats, hepatic steatosis was microvesicular in six of seven (Figure 5c), and macrovesicular in six of seven (Figure 5d) livers. In control animals, hepatic steatosis was microvesicular in 2 of 10 and macrovesicular in 3 of 10 livers. Alcohol and control rats differed significantly for the presence and severity of macrovesicular $(p=0.0009)$ and microvesicular $(p=0.0032)$ lipidosis. An additional significant difference $(p=0.0007)$ between groups was the presence of minimal hepatic glycogenosis in two of seven alcohol rats, whereas all ten control animals exhibited glycogenosis. Hepatic glycogenosis was subgrossly midzonal in distribution, and morphologically appeared as clear, negatively staining floccular material that displaced the normal eosinophilic cytoplasm of hepatocytes (Figure $5 b$ ).

Simple regression analysis included all rats to test relations between changes in liver morphology, metabolite 

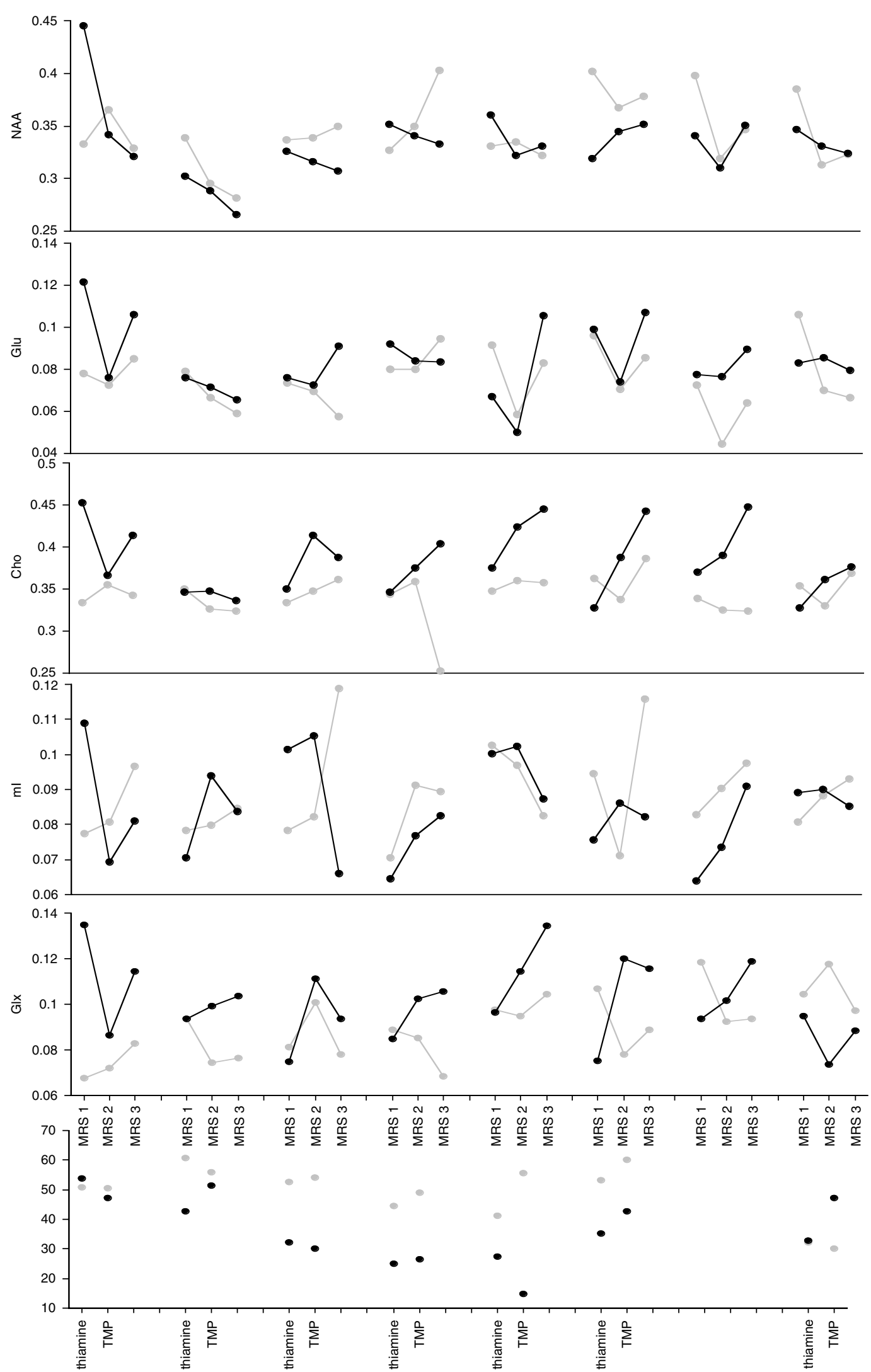

Figure 3 Metabolite levels plotted by sibling pairs (alcohol-exposed is in black; control is in gray) at each MRI session for the 8 pairs that were available for the 3 scanning sessions. Thiamine and TMP levels at MRS 3, by sibling pairs, are also plotted. 
levels at MRS 3, and thiamine status. Greater presence and severity of microvesicular lipidosis correlated with higher levels of Glu ( $\rho=0.65, p=0.0095$; Figure 5e) at MRS 3. Greater presence and severity of macrovesicular lipidosis correlated with higher levels of Cho at MRS $3(\rho=0.51$, $p=0.0408$; Figure 5f). Higher Cho $(\rho=-0.51, p=0.0412)$, Glx $(\rho=-0.64, p=0.0105)$, and Glu $(\rho=-0.53, p=0.0333)$ at MRS 3 also correlated with absent or minimal glycogenosis. Macro- and microvesicular lipidosis each correlated with thiamine (macrovesicular, $\rho=-0.76$, $p=0.0025$; microvesicular, $\rho=-0.51, p=0.041)$ and TMP (macrovesicular, $\rho=-0.63, \quad p=0.0117$; microvesicular, $\rho=-0.61, p=0.0142$ ) levels.

\section{Behavior}

Rotarod testing of balance maintenance did not differentiate the groups at any experimental test session. By contrast, neurological examination revealed more signs in the alcohol than control group. At MRS 2, six of eight of the alcohol rats and none of the ten controls exhibited neurological signs on 2 consecutive days. Neurological signs persisted when rats were again tested just before MRS 3, with all eight of the alcohol rats and none of the controls exhibiting signs on 2 consecutive testing days (Figure 6). Frequently observed neurological signs included altered motor (loss of righting reflex, stereotypy, tremor) and autonomic (palpebral closure, excessive lacrimation, and nasal discharge) functions.

\section{DISCUSSION}

Effects of BALs as high as $\sim 445 \mathrm{mg}$ per $100 \mathrm{ml}$ are rarely reported in the literature. Such high levels are difficult to

Table 3 Thiamine and Its Phosphates (in nmol/l): Means and Standard Deviations

\begin{tabular}{lccc}
\hline & Thiamine & TMP & TPP \\
\hline Alcohol $(n=7)$ & $35.63 \pm 9.79$ & $37.16 \pm 13.56$ & $0.872 \pm 0.06$ \\
Control $(n=10)$ & $49.93 \pm 8.68$ & $52.85 \pm 14.23$ & $0.884 \pm 0.04$ \\
p-value & 0.0063 & 0.0377 & 0.6409 \\
\hline
\end{tabular}

Abbreviations: TMP, thiamine monophosphate; TPP, thiamine pyrophosphate.

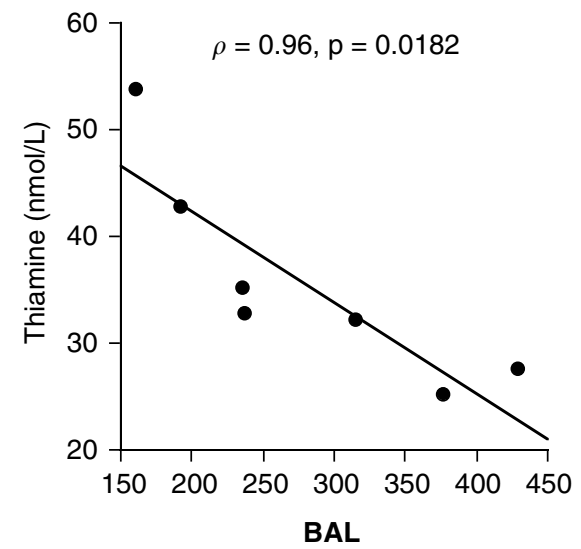

achieve with two-bottle free-choice paradigms, would require prohibitively high volumes by intraperitoneal or intragastric injections, or require extended longitudinal exposure with alcohol vapor, as BALs of $\sim 250 \mathrm{mg}$ per $100 \mathrm{ml}$ are typically reported with exposure times of $\sim 2$ weeks (Slawecki, 2006). The group of rats used in this experiment also underwent structural MRI evaluation, quantified with atlas-based parcellation, and revealed a profile of significant ventricular expansion after alcohol vapor exposure. In particular, from MRI 1 to MRI 3, ventricular volume expanded by an average of $8.0 \%$ in the controls and by $29.5 \%$ in the alcohol-exposed rats (Pfefferbaum et al, 2008).

The discussion reviews the following key findings: higher Cho at BALs of $\sim 293 \mathrm{mg}$ per $100 \mathrm{ml}$ and higher Cho, Glx, and Glu at BALs of $\sim 445 \mathrm{mg}$ per $100 \mathrm{ml}$ in the alcohol relative to control group; significantly lower thiamine (28.6\%) and TMP (29.7\%) levels in the alcohol than the control group; greater steatosis and lower glycogenosis in the alcoholic compared to control groups; and relevant correlations.

\section{Metabolites}

MRS data were acquired in rats after 16 and 24 weeks of alcohol exposure and while still in an acutely intoxicated state (within $8 \mathrm{~h}$ of alcohol exposure). The most significant MRS finding was an increase in basal ganglia Cho with escalating alcohol exposure. In cross-sectional studies, the parietal gray matter of actively drinking alcohol-dependent subjects (Meyerhoff et al, 2004), and the frontal white matter and anterior cingulate areas of social drinkers (Ende et al, 2006) demonstrate higher Cho levels than controls. Our data are also in agreement with the rodent study by Lee et al (2003), who showed an increase in Cho after 16 weeks of forced choice alcohol exposure. Lee et al found that at week 16 of alcohol exposure, their control group had a Cho/ NAA ratio of $0.44 \pm 0.04$, whereas the alcohol group had a ratio of $0.54 \pm 0.09,22.7 \%$ greater levels than controls. In our study, at week 16 of exposure, the alcohol group (Cho/ $\mathrm{NAA}=1.18 \pm 0.1)$ had $14.6 \%$ higher Cho than the control group $(\mathrm{Cho} / \mathrm{NAA}=1.03 \pm 0.06)$. At week 24 , the alcohol group $(\mathrm{Cho} / \mathrm{NAA}=1.26 \pm 0.05)$ had $23.5 \%$ higher Cho than the control group $(\mathrm{Cho} / \mathrm{NAA}=1.02 \pm 0.15)$. This converging

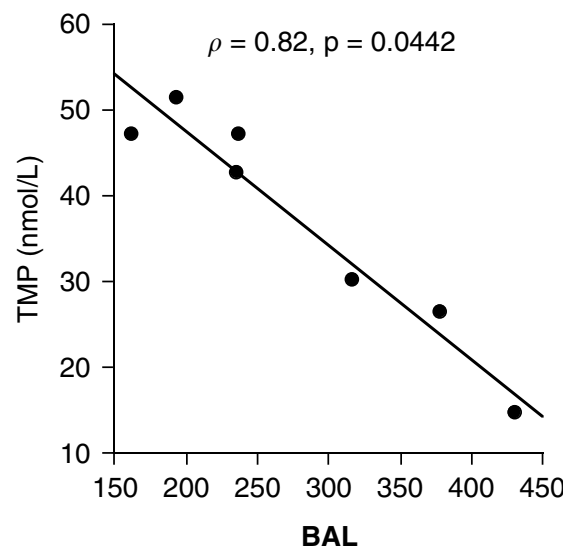

Figure 4 Scatter plots of a simple regression between alcohol rats' BALs shortly before MRS 3 and plasma thiamine and TMP levels at the termination of the experiment. Higher BALs correlate with lower thiamine and TMP levels. 


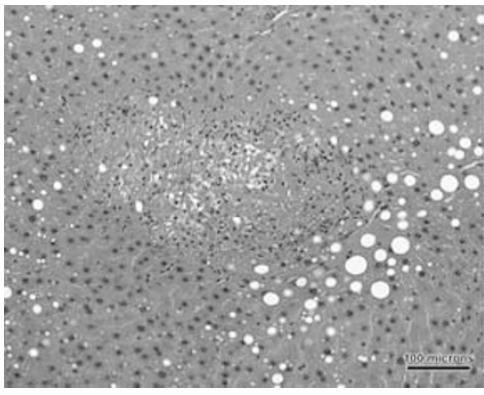

C
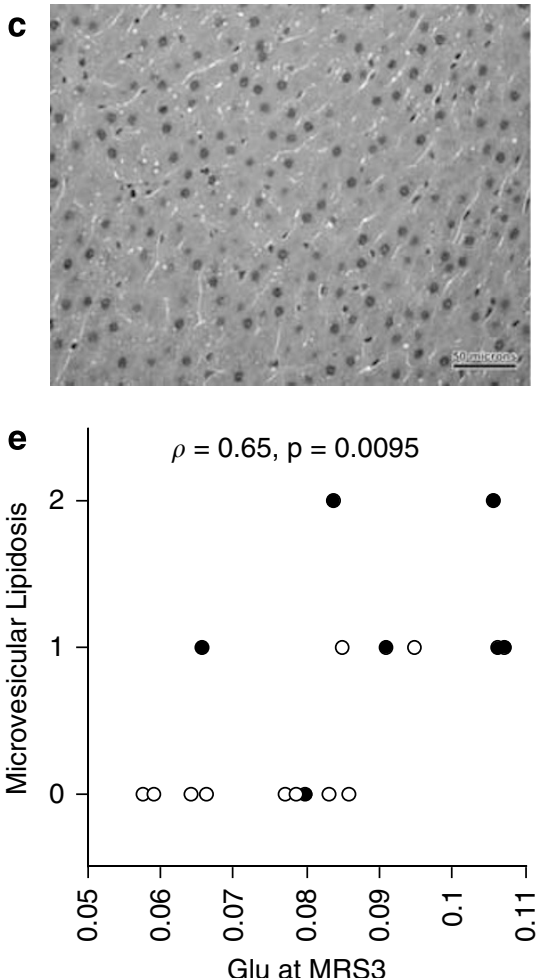

b

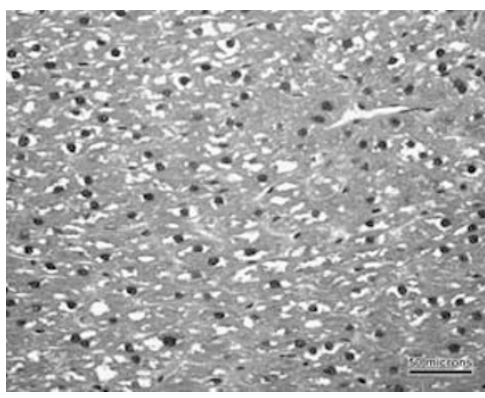

d

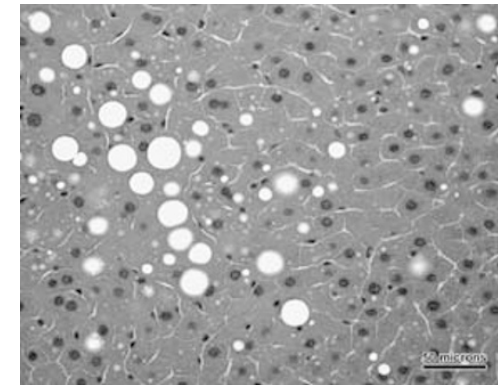

$f$

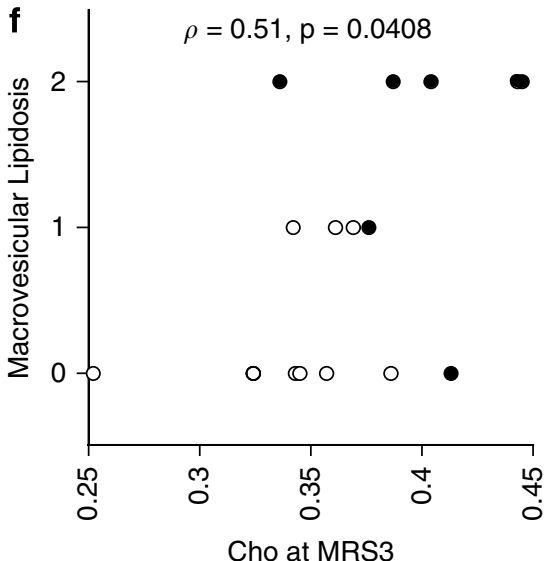

Figure 5 Left lateral lobe liver specimens from alcohol-exposed animals (a, c, and d) and a control animal (b) were H\&E stained. (a) Focal area of hepatocellular necrosis. (b) Hepatic glycogenosis. (c) Minimal microvesicular hepatic steatosis. (d) Mild macrovesicular hepatic steatosis. (e) Higher Glu at MRS 3 associated with increased presence and severity of microvesicular lipidosis. (f) Higher Cho at MRS 3 associated with increased presence and severity of macrovesicular lipidosis.

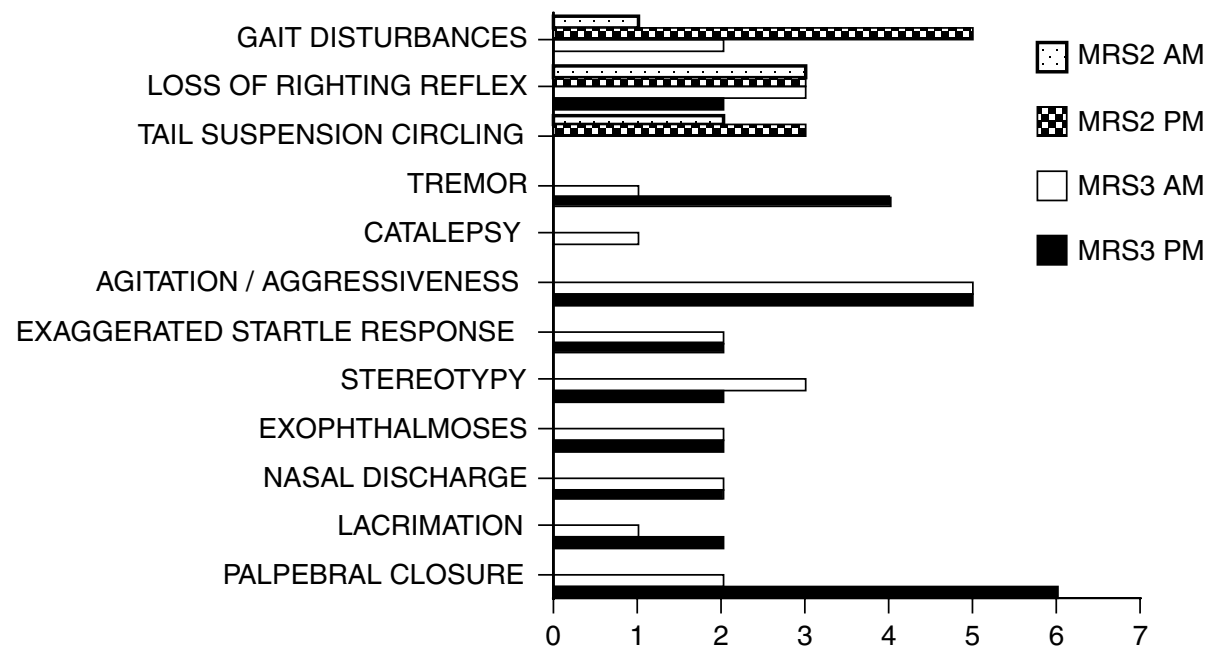

Figure 6 Frequency of neurological signs for 8 alcohol rats before MRS 2 and MRS 3. 
evidence suggests that alcohol per se leads to an increase in Cho. Although many human studies report lower Cho in alcoholics than controls (Bendszus et al, 2001; Durazzo et al, 2004; Jagannathan et al, 1996; Miese et al, 2006; Murata et al, 2001; but see O'Neill et al, 2001; Parks et al, 2002; Seitz et al, 1999), we speculate that low Cho can be explained by undetected or subclinical pathologies, including thiamine deficiency or liver cirrhosis, also associated with low Cho levels (Cordoba et al, 2001; Geissler et al, 1997; Kreis et al, 1992; Ross et al, 1994). Interestingly, in an MRS study of recently detoxified alcoholics where care was taken to exclude patients with liver disease or malnutrition, no differences in Cho were apparent between alcoholics and controls in frontal or parietal white matter (Schweinsburg et al, 2001). As Cho is elevated in multiple sclerosis (Srinivasan et al, 2005), human immunodeficiency virus infection (Ernst et al, 2003), and normal aging (Pfefferbaum et al, 1999; Zahr et al, 2008), is higher in white than gray matter (Pfefferbaum et al, 1999), and is more highly concentrated in glial than neuronal cells (Brand et al, 1993; Urenjak et al, 1993), elevated Cho has been interpreted as indicative of demyelination, inflammation, or abnormally high glial density (De Stefano et al, 2005; Lin et al, 2005). Given the known effects of alcohol on membrane phospholipids (Aloia et al, 1985; Le Bourhis et $a l, 1986)$, one likely interpretation for the effects of alcohol on Cho is cell membrane disruption due to changes in the contributions of the free Cho, phosphocholine, and glycerophosphocholine to the MRS-detectable Cho signal (Denays et al, 1993; Griffin et al, 2001). Alternatively, a recent study indicated that the brains of alcoholic humans express higher levels of monocyte chemotactic protein-1, a key proinflammatory cytokine than controls (He and Crews, 2008), suggesting that the increase in Cho could reflect alcohol-induced inflammatory processes. Mice lacking the tumor necrosis factor (TNF) $\alpha$ receptor 1 are resistant to the hepatotoxic effects of chronic ethanol (eg liver steatosis and inflammation; Yin et al, 1999). Because we observed a steatotic liver in response to chronic ethanol treatment, it may be argued that alcoholized rats produced $\mathrm{TNF} \alpha$, ie the livers recruited an early inflammatory response (Hines and Wheeler, 2004). Given the findings of a lipopolysaccharide model (Qin et al, 2004), it is suggested that systemic TNF $\alpha$ enters the brain to induce neuroinflammation (Crews et al, 2006). Transgenic mice with constitutively expressed brain $\mathrm{TNF} \alpha$ develop demyelinating inflammation (Probert et al, 1995). As already mentioned, elevations in Cho are often seen in demyelinating inflammatory diseases (eg multiple sclerosis; Mader et al, 2008), and we observed elevated Cho in response to chronic vaporized ethanol. Thus, inasmuch as inflammation in the brain may be indicated by elevated levels of Cho, which may result from the immune cascade initiated by elevated TNF $\alpha$ levels in the brain, it is possible that the Cho elevation we observed is in response to an inflammatory cascade instigated by ethanol's effects in the liver.

We also demonstrated that the Glx peak increased with escalating alcohol exposure. Few studies note alterations to the Glx peak in uncomplicated alcoholism, although in alcohol-related liver disease, such as cirrhosis, an increase in Glx is one of the three neurospectroscopic abnormalities reported (Geissler et al, 1997; Kreis et al, 1992; Lee et al, 1999); further discussed in the section on liver histopathology).

A possible mechanism for the increase in Cho and Glx is alcohol-induced increase in serum osmolality, as there is a strong correlation between blood alcohol concentration and serum osmolality (Champion et al, 1975). Clinical brain spectroscopy of patients with cirrhosis-associated hyponatremia demonstrated correlations of $\mathrm{mI}$, Cho, $\mathrm{tCr}$, and NAA (but not Glu, the concentration of which is influenced by ammonia levels) with serum sodium levels (Restuccia et al, 2004). As with $\mathrm{mI}$, Tau, which is abundant in rat brain, is also know to be involved in osmotic regulation (Olson and Martinho, 2006; Zwingmann et al, 2004) and increases and decreases with serum osmolality. In the current study, it is unlikely that serum osmolality is the entire explanation for the increases in Cho and Glx, because other metabolites affected by osmolality, notably NAA, Tau, and $\mathrm{mI}$, were lower in the alcohol-treated conditions.

\section{Thiamine and Phosphate Derivatives}

Despite the well-known association between alcoholism and thiamine deficiency (Harper, 2006; Martin et al, 2003; Thomson, 2000), thiamine levels are difficult to evaluate and rarely reported in alcohol studies. Attempts to determine thiamine levels using microbiological assays and functional estimates based on erythrocyte transketolase activity tend to be insensitive and nonspecific (Lynch and Young, 2000). The use of LC-MS allows for increased sensitivity and chromatographic separation of thiamine compounds, including TMP and TPP. HPLC methods report values ranging from 4.0 (Herve et al, 1994) to $89.6 \mathrm{nmol} / \mathrm{l}$ (Mancinelli et al, 2003) for thiamine concentration in healthy human blood. This wide range is likely related to the blood constituent sampled, ie whole blood, plasma, or erythrocytes (Herve et al, 1995; Levy et al, 2002; Lynch and Young, 2000).

TMP has been reported as similar across groups in erythrocyte samples (36 alcohol-dependent patients, 9 with liver cirrhosis; Mancinelli et al, 2003), 50\% lower in serum samples (30 alcohol-dependent patients; Tallaksen et al, $1992 \mathrm{~b}$ ), and $82 \%$ lower in plasma samples (22 patients with alcohol-induced liver cirrhosis; Tallaksen et al, 1992a) from patients compared with controls. The $30 \%$ reduction in TMP observed herein is closest to the change reported in serum samples from the study including only alcoholdependent patients (Tallaksen et al, 1992b). Both studies reporting decreases in thiamine levels included alcoholic patients with liver cirrhosis (22\% decrease, Mancinelli et al, 2003; 27\% decrease, Tallaksen et al, 1992a), whereas in the absence of notable liver disease, thiamine levels in alcoholics are indistinguishable from controls (Tallaksen et al, 1992b). The $29 \%$ reduction in thiamine in our alcoholexposed rats is in close agreement with the studies in human patients with cirrhosis, and may reflect the mild liver steatosis observed. Only the study using erythrocyte samples reports a difference in TPP levels between alcoholics and controls (43\% lower in alcoholics; Mancinelli et al, 2003), which may be explained by the fact that TPP is found predominantly in erythrocytes (Mancinelli et al, 2003; Tallaksen et al, 1997). Indeed, the lack of alcohol effects on TPP levels in this study may be because plasma 
rather than an erythrocyte sample was assayed and suggests that future studies measure thiamine and its derivatives in a rinsed red blood cell sample (Mancinelli et al, 2003).

A lack of correlation in the alcohol group between thiamine levels and brain metabolites may be explained by the relatively small changes observed in the plasma levels of thiamine and TMP. The brain has multiple homeostatic mechanisms for maintaining thiamine, TMP, and TPP levels, despite fluctuations in blood (Spector, 1976). Blood levels must fall significantly, for example, with pyrithiamine hydrobromide treatments in rodents (Langlais and Savage, 1995; Lee et al, 2001; Navarro et al, 2005; Pfefferbaum et al, 2007; Savage et al, 1999) or with severe liver disease in humans (Kreis et al, 1992; Laubenberger et al, 1997; Lee et al, 1999) before thiamine, TMP, and TPP levels are sufficiently altered to influence the brain. Indeed, neurological symptoms of thiamine deficiency are not observed in rodents treated with pyrithiamine hydrobromide until brain levels of TMP and TPP are 85\% lower than normal values, when thiamine status as measured by the erythrocyte transketolase assay is at least $40 \%$ lower than normal values (Heroux and [10]Butterworth, 1995).

\section{Liver Histopathology}

Histopathological assessment of alcohol-exposed rat livers revealed an absence of hepatitis or cirrhosis. Nevertheless, rats exposed to vaporized alcohol for a total 24 weeks exhibited greater steatosis, and lower glycogenosis relative to controls. As fatty liver is the earliest and most common hepatic consequence of alcohol ingestion in humans, whereas hepatitis and cirrhosis require sustained, longterm ingestion (French et al, 1993; Nanji et al, 1989), the results observed in this study suggest that the length of alcohol exposure was sufficient to produce only mild (grade 2 steatosis) liver pathology. Previous studies have demonstrated the presence of fatty livers in rodents given chronic intragastric ethanol and low (Tsukamoto et al, 1985) or minimal fat (Nanji et al, 1989; Walker and Gordon, 1970) diets. Liver pathologies have also been noted in studies using vaporized ethanol administration. Di Luzio and Stege (1979) demonstrated a significant elevation in liver triglycerides in rats exposed to vaporized ethanol at days 3, 6, and 9 of exposure, whereas Rouach et al (1984) demonstrated that ethanol inhalation for 2 days changes the fatty acid distribution of mitochondrial liver phospholipids. Together, these findings suggest that ethanol may induce the excessive accumulation of lipids in the liver (ie steatosis) directly, without primary changes in the gut. Steatosis could result from hypoxia (Knecht et al, 1995) induced directly by alcohol (Bode and Bode, 2005). Alternatively, as vaporized ethanol treatment has been shown to induce P450s (nonspecified subtype; Morgan et al, 1981), the metabolism of ethanol to acetaldehyde through cytochrome P450 2E1 may be another mechanism associated with a direct alcohol insult to the liver (Lieber, 2004). The decreased glycogenolysis observed in the alcoholtreated animals in this study is in agreement with several studies demonstrating an association between chronic ethanol exposure and decreased hepatic glycogen levels (Kaminsky and Kosenko, 1986; Nanji et al, 1995; Sumida et al, 2007; Walker and Gordon, 1970). Indeed, an increase in hepatic triglyceride content has been associated with a decrease in glycogen (Walker and Gordon, 1970).

The association between glycogenolysis (lower) and Glx (higher) is notable in that human studies often report abnormally high Glx levels in patients with acute liver failure (Bosman et al, 1990; Geissler et al, 1997; Gupta et al, 1993; Laubenberger et al, 1997), subclinical hepatic encephalopathy (Ross et al, 1994), and chronic hepatic encephalopathy (Kreis et al, 1990, 1992). These observations have led to the supposition that Glx levels increase in proportion to the severity of dysfunction (Ross et al, 1994). The explanation frequently given for the Glx elevation is that in liver dysfunction levels of blood ammonia increase. The brain compensates for hyperammonia by increasing the production of glutamine through the action of glutamine synthetase (Bates et al, 1989; Cooper and Plum, 1987), located primarily in brain astrocytes, and potentially altering astrocytic morphology (Felipo and Butterworth, 2002; Laubenberger et al, 1997; Norenberg et al, 2007; Peeling et al, 1993). In vitro reports regarding liver failure, however, describe an increase in glutamine and an associated decrease in Glu (Peeling et al, 1993; Swain et al, 1992; Zimmermann et al, 1989), whereas in the current study, increases in Glu and Glx were observed, militating against the conclusion that brain metabolite or structural changes could be attributed to liver failure per se.

The correlations between mild macro- and microvesicular lipidosis, thiamine, and TMP levels are in agreement with findings that chronic liver disease alters thiamine homeostasis (Butterworth, 1995). Alcoholics with severe liver cirrhosis have a higher incidence of thiamine deficiency as reflected by erythrocyte transketolase activation compared to alcoholics lacking hepatic abnormalities (Somogyi et al, 1980). The current findings indicate that even mild liver dysfunction in the form of steatosis may alter thiamine status, suggesting a graded effect such that the degree of liver damage correlates with severity of thiamine deficiency.

\section{Behavior}

Neurological signs present in the morning at MRS 2 when rats were intoxicated included gait disturbances, loss of righting reflex, and circling with tail suspension. After 8-10 h without alcohol, these three signs were still present, although gait disturbances became evident in more animals. At MRS 3, the frequency and number of neurological signs became more pronounced. While intoxicated, rats exhibited exophthalmoses, excessive nasal discharge and lacrimation, palpebral closure, agitation and aggressiveness, catalepsy, an exaggerated startle response, tremor, stereotypy, loss of righting reflex, and gait disturbances. After 8-10 h without alcohol, catalepsy and gait disturbances were no longer observed, but more rats exhibited palpebral closure and tremor. There were no correlations between presence of neurological signs and any of the metabolites measured.

In humans with chronic alcohol exposure, withdrawal behaviors are expressed between $4 \mathrm{~h}$ and 4 days after the last dose of alcohol (Becker, 2000). Although behavioral signs and symptoms are evident as soon as $4 \mathrm{~h}$ after the last dose, seizures usually occur within $48 \mathrm{~h}$ of alcohol cessation, and delirium tremens within 4 days (Becker, 
2000); peak intensity of withdrawal behavior typically occurs during the second day of abstinence. In this report, the absence of protracted withdrawal refers to the 'acute' (at most $12 \mathrm{~h}$ ) withdrawal period, before 'severe' withdrawal signs such as seizures or delirium tremens typically emerge.

\section{Model of Metabolic Patterns Distinguishing Intoxication, Withdrawal, and Thiamine Status}

An ideal study to distinguish alcohol-induced MRSdetectable changes in metabolite patterns from incidental factors would include several additional treatment groups. For example, a dose-response paradigm would include two groups with the same alcohol exposure time, but given two different levels of alcohol. Also, groups of animals could have undergone a protracted withdrawal period or could have been treated with pyrithiamine hydrobromide to induce severe thiamine deficiency, or a liver toxin such as carbon tetrachloride to induce liver damage. Such a study was beyond the scope of this initial investigation using longitudinal MRS and the vapor chamber system to expose rats to high and prolonged doses of alcohol.

Unlike previous MRS studies of rodent alcohol models, the current report monitored BALs, thiamine, and liver status. This study demonstrates significant modulation of brain metabolites attributable to high levels of blood alcohol $(\sim 445 \mathrm{mg}$ per $100 \mathrm{ml})$. The metabolite pattern in detoxified, abstinent human alcoholics includes lower levels of NAA and Cho, a pattern also seen in thiamine deficiency MRS studies in both humans and rats. In liver disease, including cirrhosis and hepatic encephalopathy, lower Cho is also noted, accompanied by lower $\mathrm{mI}$ and Glu and higher levels of Glx. The concurrent increase in Cho and Glx observed in the current study is a pattern also reported in another study of MRS-detectable alcohol effects, the longitudinal rodent study by Lee et al (2003). The observed modulation of brain chemistry-absent protracted withdrawal, pronounced thiamine deficiency, or severe liver pathology - suggests that these changes are at least in part the effects of alcohol perse.

\section{ABBREVIATIONS}

ANOVA, analysis of variance; BALs, blood alcohol levels; Cho, choline; CS, chemical shift; CT-PRESS, constant time point resolved spectroscopy; Glu, glutamate; Glx, glutamine + glutamate; HPLC, high-performance liquid chromatography; LC-MS, liquid chromatography-mass spectrometer; mI, myo-inositol; MR, magnetic resonance; MRS, magnetic resonance spectroscopy; NAA, N-acetylaspartate; SW, spectral width; Tau, taurine; $\mathrm{tCr}$, total creatine; TE, echo time; TMP, thiamine monophosphate; TNF, tumor necrosis factor; TPP, thiamine pyrophosphate; TR, repetition time.

\section{ACKNOWLEDGEMENTS}

This research was supported by grants to AP by the National Institute on Alcohol Abuse and Alcoholism (AA013521-INIA, AA005965).

\section{DISCLOSURE/CONFLICT OF INTEREST}

The authors have no conflict of interest, financial or otherwise.

\section{REFERENCES}

Adalsteinsson E, Hurd RE, Mayer D, Sailasuta N, Sullivan EV, Pfefferbaum A (2004). In vivo 2D J-resolved magnetic resonance spectroscopy of rat brain with a 3-T clinical human scanner. Neuroimage 22: 381-386.

Aloia RC, Paxton J, Daviau JS, van Gelb O, Mlekusch W, Truppe W et al (1985). Effect of chronic alcohol consumption on rat brain microsome lipid composition, membrane fluidity and $\mathrm{Na}+\mathrm{K}+-$ ATPase activity. Life Sciences 36: 1003-1017.

Anand BS (1999). Cirrhosis of liver. West J Med 171: 110-115.

Bates TE, Williams SR, Kauppinen RA, Gadian DG (1989). Observation of cerebral metabolites in an animal model of acute liver failure in vivo: a $1 \mathrm{H}$ and $31 \mathrm{P}$ nuclear magnetic resonance study. J Neurochem 53: 102-110.

Becker HC (2000). Animal models of alcohol withdrawal. Alcohol Res Health 24: 105-113.

Bendszus M, Weijers HG, Wiesbeck G, Warmuth-Metz M, Bartsch AJ, Engels S et al (2001). Sequential MR imaging and proton MR spectroscopy in patients who underwent recent detoxification for chronic alcoholism: correlation with clinical and neuropsychological data. Am J Neuroradiol 22: 1926-1932.

Bode C, Bode JC (2005). Activation of the innate immune system and alcoholic liver disease: effects of ethanol per se or enhanced intestinal translocation of bacterial toxins induced by ethanol? Alcohol Clin Exp Res 29: 166S-171S.

Bosman DK, Deutz NE, De Graaf AA, vd Hulst RW, Van Eijk HM, Bovee WM et al (1990). Changes in brain metabolism during hyperammonemia and acute liver failure: results of a comparative $1 \mathrm{H}-\mathrm{NMR}$ spectroscopy and biochemical investigation. Hepatology 12: 281-290.

Brand A, Richter-Landsberg C, Leibfritz D (1993). Multinuclear NMR studies on the energy metabolism of glial and neuronal cells. Dev Neurosci 15: 289-298.

Butterworth RF (1995). Pathophysiology of alcoholic brain damage: synergistic effects of ethanol, thiamine deficiency and alcoholic liver disease. Metab Brain Dis 10: 1-8.

Champion HR, Baker SP, Benner C, Fisher R, Caplan YH, Long WB et al (1975). Alcohol intoxication and serum osmolality. Lancet 1: 1402-1404.

Cooper AJ, Plum F (1987). Biochemistry and physiology of brain ammonia. Physiol Rev 67: 440-519.

Cordoba J, Alonso J, Rovira A, Jacas C, Sanpedro F, Castells L et al (2001). The development of low-grade cerebral edema in cirrhosis is supported by the evolution of (1) H-magnetic resonance abnormalities after liver transplantation. J Hepatol 35: 598-604.

Cordoba J, Sanpedro F, Alonso J, Rovira A (2002). 1H magnetic resonance in the study of hepatic encephalopathy in humans. Metab Brain Dis 17: 415-429.

Crews FT, Bechara R, Brown LA, Guidot DM, Mandrekar P, Oak S et al (2006). Cytokines and alcohol. Alcohol Clin Exp Res 30: 720-730.

De Stefano N, Bartolozzi ML, Guidi L, Stromillo ML, Federico A (2005). Magnetic resonance spectroscopy as a measure of brain damage in multiple sclerosis. J Neurol Sci 233: 203-208.

Denays R, Chao SL, Mathur-Devre R, Jeghers O, Fruhling J, Noel P et al (1993). Metabolic changes in the rat brain after acute and chronic ethanol intoxication: a 31P NMR spectroscopy study. Magn Reson Med 29: 719-723.

Di Luzio NR, Stege TE (1979). Influence of chronic ethanol vapor inhalation on hepatic parenchymal and Kupffer cell function. Alcohol Clin Exp Res 3: 240-247. 
Durazzo TC, Gazdzinski S, Banys P, Meyerhoff DJ (2004). Cigarette smoking exacerbates chronic alcohol-induced brain damage: a preliminary metabolite imaging study. Alcohol Clin Exp Res 28: $1849-1860$.

Ende G, Walter S, Welzel H, Demirakca T, Wokrina T, Ruf M et al (2006). Alcohol consumption significantly influences the MR signal of frontal choline-containing compounds. Neuroimage 32: 740-746.

Ernst T, Chang L, Arnold S (2003). Increased glial metabolites predict increased working memory network activation in HIV brain injury. Neuroimage 19: 1686-1693.

Ernst T, Chang L, Melchor R, Mehringer CM (1997). Frontotemporal dementia and early Alzheimer disease: differentiation with frontal lobe H-1 MR spectroscopy. Radiology 203: 829-836.

Felipo V, Butterworth RF (2002). Neurobiology of ammonia. Prog Neurobiol 67: 259-279.

French SW, Nash J, Shitabata P, Kachi K, Hara C, Chedid A et al (1993). Pathology of alcoholic liver disease. VA Cooperative Study Group 119. Semin Liver Dis 13: 154-169.

Geissler A, Lock G, Frund R, Held P, Hollerbach S, Andus T et al (1997). Cerebral abnormalities in patients with cirrhosis detected by proton magnetic resonance spectroscopy and magnetic resonance imaging. Hepatology 25: 48-54.

Griffin JL, Mann CJ, Scott J, Shoulders CC, Nicholson JK (2001). Choline containing metabolites during cell transfection: an insight into magnetic resonance spectroscopy detectable changes. FEBS Lett 509: 263-266.

Gupta RK, Saraswat VA, Poptani H, Dhiman RK, Kohli A, Gujral $\mathrm{RB}$ et al (1993). Magnetic resonance imaging and localized in vivo proton spectroscopy in patients with fulminant hepatic failure. Am J Gastroenterol 88: 670-674.

Harper C (2006). Thiamine (vitamin B1) deficiency and associated brain damage is still common throughout the world and prevention is simple and safe!. Eur J Neurol 13: 1078-1082.

$\mathrm{He}$ J, Crews FT (2008). Increased MCP-1 and microglia in various regions of the human alcoholic brain. Exp Neurol 210: 349-358.

Heroux M, Butterworth RF (1995). Regional alterations of thiamine phosphate esters and of thiamine diphosphate-dependent enzymes in relation to function in experimental Wernicke's encephalopathy. Neurochem Res 20: 87-93.

Herve C, Beyne P, Delacoux E (1994). Determination of thiamine and its phosphate esters in human erythrocytes by highperformance liquid chromatography with isocratic elution. J Chromatogr B Biomed Appl 653: 217-220.

Herve C, Beyne P, Letteron P, Delacoux E (1995). Comparison of erythrocyte transketolase activity with thiamine and thiamine phosphate ester levels in chronic alcoholic patients. Clin Chim Acta 234: 91-100.

Hines IN, Wheeler MD (2004). Recent advances in alcoholic liver disease III. Role of the innate immune response in alcoholic hepatitis. Am J Physiol 287: G310-G314.

Jagannathan NR, Desai NG, Raghunathan P (1996). Brain metabolite changes in alcoholism: an in vivo proton magnetic resonance spectroscopy (MRS) study. Magn Reson Imaging 14: 553-557.

Kaminsky YG, Kosenko EA (1986). Blood glucose and liver glycogen in the rat. Effects of chronic ethanol consumption and its withdrawal on the diurnal rhythms. FEBS Lett 200: 217-220.

Knecht KT, Adachi Y, Bradford BU, Iimuro Y, Kadiiska M, Xuang QH et al (1995). Free radical adducts in the bile of rats treated chronically with intragastric alcohol: inhibition by destruction of Kupffer cells. Mol Pharmacol 47: 1028-1034.

Kreis R, Farrow N, Ross BD (1990). Diagnosis of hepatic encephalopathy by cerebral proton magnetic resonance spectroscopy. Lancet 336: 635-636.
Kreis R, Ross BD, Farrow NA, Ackerman Z (1992). Metabolic disorders of the brain in chronic hepatic encephalopathy detected with H-1 MR spectroscopy. Radiology 182: 19-27.

Langlais PJ, Savage LM (1995). Thiamine deficiency in rats produces cognitive and memory deficits on spatial tasks that correlate with tissue loss in diencephalon, cortex and white matter. Behav Brain Res 68: 75-89.

Laubenberger J, Haussinger D, Bayer S, Gufler H, Hennig J, Langer $M$ (1997). Proton magnetic resonance spectroscopy of the brain in symptomatic and asymptomatic patients with liver cirrhosis. Gastroenterology 112: 1610-1616.

Le Bourhis B, Beauge F, Aufrere G, Nordmann R (1986). Membrane fluidity and alcohol dependence. Alcohol Clin Exp Res 10: 337-342.

Lee H, Holburn GE, Price RR (2001). In vivo and in vitro proton NMR spectroscopic studies of thiamine-deficient rat brains. J Magn Reson Imaging 13: 163-166.

Lee H, Holburn GH, Price RR (2003). Proton MR spectroscopic studies of chronic alcohol exposure on the rat brain. J Magn Reson Imaging 18: 147-151.

Lee H, Tarter J, Holbourn GE, Price RR, Weinstein DD, Martin PR (1995). In vivo localized proton NMR spectroscopy of thiaminedeficient rat brain. Magn Reson Med 34: 313-318.

Lee JH, Seo DW, Lee YS, Kim ST, Mun CW, Lim TH et al (1999). Proton magnetic resonance spectroscopy (1H-MRS) findings for the brain in patients with liver cirrhosis reflect the hepatic functional reserve. Am J Gastroenterol 94: 2206-2213.

Levy S, Herve C, Delacoux E, Erlinger S (2002). Thiamine deficiency in hepatitis $\mathrm{C}$ virus and alcohol-related liver diseases. Dig Dis Sci 47: 543-548.

Lieber CS (2004). Alcoholic fatty liver: its pathogenesis and mechanism of progression to inflammation and fibrosis. Alcohol 34: 9-19.

Lien Y, Shapiro J, Chan L (1990). Effects of hypernatremia on organic brain osmoles. J Clin Investig 85: 1427-1435.

Lin A, Ross BD, Harris K, Wong W (2005). Efficacy of proton magnetic resonance spectroscopy in neurological diagnosis and neurotherapeutic decision making. NeuroRx 2: 197-214.

Lynch PL, Young IS (2000). Determination of thiamine by highperformance liquid chromatography. J Chromatogr A 881: 267-284.

Mader I, Rauer S, Gall P, Klose U (2008). (1)H MR spectroscopy of inflammation, infection and ischemia of the brain. Eur J Radiol 67: 250-257.

Mancinelli R, Ceccanti M, Guiducci MS, Sasso GF, Sebastiani G, Attilia ML et al (2003). Simultaneous liquid chromatographic assessment of thiamine, thiamine monophosphate and thiamine diphosphate in human erythrocytes: a study on alcoholics. J Chromatogr B Analyt Technol Biomed Life Sci 789: 355-363.

Martin PR, Singleton CK, Hiller-Sturmhofel S (2003). The role of thiamine deficiency in alcoholic brain disease. Alcohol Res Health 27: 134-142.

Mascalchi M, Belli G, Guerrini L, Nistri M, Del Seppia I, Villari N (2002). Proton MR spectroscopy of Wernicke encephalopathy. AJNR 23: 1803-1806.

Mayer D, Spielman DM (2005a). Detection of glutamate in the human brain at $3 \mathrm{~T}$ using optimized constant time point resolved spectroscopy. Magn Reson Med 54: 439-442.

Mayer D, Spielman DM (2005b). Detection of glutamate in the human brain at $3 \mathrm{~T}$ using optimized constant time point resolved spectroscopy. Magn Reson Med 54: 439-442.

Mayer D, Zahr NM, Adalsteinsson E, Rutt B, Sullivan EV, Pfefferbaum A (2007a). In vivo fiber tracking in the rat brain on a clinical $3 \mathrm{~T}$ MRI system using a high strength insert gradient coil. Neuroimage 35: 1077-1085.

Mayer D, Zahr NM, Sullivan EV, Pfefferbaum A (2007b). In vivo metabolite differences between the basal ganglia and cerebellum of the rat brain detected with proton MRS at 3T. Psychiatry Res 154: $267-273$. 
Meyerhoff DJ, Blumenfeld R, Truran D, Lindgren J, Flenniken D, Cardenas V et al (2004). Effects of heavy drinking, binge drinking, and family history of alcoholism on regional brain metabolites. Alcohol Clin Exp Res 28: 650-661.

Miese F, Kircheis G, Wittsack HJ, Wenserski F, Hemker J, Modder $\mathrm{U}$ et al (2006). 1H-MR spectroscopy, magnetization transfer, and diffusion-weighted imaging in alcoholic and nonalcoholic patients with cirrhosis with hepatic encephalopathy. AJNR 27: 1019-1026.

Modell JG, Mountz JM, Beresford TP (1990). Basal ganglia/limbic striatal and thalamocortical involvement in craving and loss of control in alcoholism. J Neuropsychiatry 2: 123-144.

Morgan ET, Devine M, Skett P (1981). Changes in the rat hepatic mixed function oxidase system associated with chronic ethanol vapor inhalation. Biochem Pharmacol 30: 595-600.

Murata T, Fujito T, Kimura H, Omori M, Itoh H, Wada Y (2001). Serial MRI and (1)H-MRS of Wernicke's encephalopathy: report of a case with remarkable cerebellar lesions on MRI. Psychiatry Res 108: 49-55.

Nanji AA, Fogt F, Griniuviene B (1995). Alterations in glucose transporter proteins in alcoholic liver disease in the rat. $A m J$ Pathol 146: 329-334.

Nanji AA, Tsukamoto H, French SW (1989). Relationship between fatty liver and subsequent development of necrosis, inflammation and fibrosis in experimental alcoholic liver disease. Exp Mol Pathol 51: 141-148.

Navarro D, Zwingmann C, Hazell AS, Butterworth RF (2005). Brain lactate synthesis in thiamine deficiency: a re-evaluation using 1H-13C nuclear magnetic resonance spectroscopy. J Neurosci Res 79: 33-41.

Norenberg MD, Jayakumar AR, Rama Rao KV, Panickar KS (2007). New concepts in the mechanism of ammonia-induced astrocyte swelling. Metab Brain Dis 22: 219-234.

O'Neill J, Cardenas VA, Meyerhoff DJ (2001). Effects of abstinence on the brain: quantitative magnetic resonance imaging and magnetic resonance spectroscopic imaging in chronic alcohol abuse. Alcoh Clin Exp Res 25: 1673-1682.

Olson JE, Martinho Jr E (2006). Regulation of taurine transport in rat hippocampal neurons by hypo-osmotic swelling. J Neurochem 96: 1375-1389.

Parks MH, Dawant BM, Riddle WR, Hartmann SL, Dietrich MS, Nickel MK et al (2002). Longitudinal brain metabolic characterization of chronic alcoholics with proton magnetic resonance spectroscopy. Alcohol Clin Exp Res 26: 1368-1380.

Paxinos G, Watson C (2005). The Rat Brain in Stereotaxic Coordinates. Elsevier Academic Press: London.

Peeling J, Shoemaker L, Gauthier T, Benarroch A, Sutherland GR, Minuk GY (1993). Cerebral metabolic and histological effects of thioacetamide-induced liver failure. Am J Physiol 265: G572-G578.

Petroff OA, Pleban LA, Spencer DD (1995). Symbiosis between in vivo and in vitro NMR spectroscopy: the creatine, $\mathrm{N}$-acetylaspartate, glutamate, and GABA content of the epileptic human brain. Magn Reson Imaging 13: 1197-1211.

Pfefferbaum A, Adalsteinsson E, Bell RL, Sullivan EV (2007). Development and resolution of brain lesions caused by pyrithiamine- and dietary-induced thiamine deficiency and alcohol exposure in the alcohol-preferring rat: a longitudinal magnetic resonance imaging and spectroscopy study. Neuropsychopharmacology 32: 1149-1177.

Pfefferbaum A, Adalsteinsson E, Spielman D, Sullivan EV, Lim KO (1999). In vivo spectroscopic quantification of the $N$-acetyl moiety, creatine and choline from large volumes of brain gray and white matter: effects of normal aging. Magn Reson Med 41: 276-284.

Pfefferbaum A, Zahr NM, Mayer D, Vinco S, Orduna J, Rohlfing T et al (2008). Ventricular expansion in wild-type Wistar rats after alcohol exposure by vapor chamber. Alcohol Clin Exp Res (in press).
Pitkin SR, Savage LM (2001). Aging potentiates the acute and chronic neurological symptoms of pyrithiamine-induced thiamine deficiency in the rodent. Behav Brain Res 119: 167-177.

Prasad S, Dhiman RK, Duseja A, Chawla YK, Sharma A, Agarwal R (2007). Lactulose improves cognitive functions and healthrelated quality of life in patients with cirrhosis who have minimal hepatic encephalopathy. Hepatology 45: 549-559.

Probert L, Akassoglou K, Pasparakis M, Kontogeorgos G, Kollias G (1995). Spontaneous inflammatory demyelinating disease in transgenic mice showing central nervous system-specific expression of tumor necrosis factor alpha. Proc Natl Acad Sci USA 92: 11294-11298.

Qin L, Liu Y, Wang T, Wei SJ, Block ML, Wilson B et al (2004). NADPH oxidase mediates lipopolysaccharide-induced neurotoxicity and proinflammatory gene expression in activated microglia. J Biol Chem 279: 1415-1421.

Restuccia T, Gomez-Anson B, Guevara M, Alessandria C, Torre A, Alayrach ME et al (2004). Effects of dilutional hyponatremia on brain organic osmolytes and water content in patients with cirrhosis. Hepatology 39: 1613-1622.

Roberts AJ, Heyser CJ, Cole M, Griffin P, Koob GF (2000). Excessive ethanol drinking following a history of dependence: animal model of allostasis. Neuropsychopharmacology 22: 581-594.

Rose SE, Nixon PF, Zelaya FO, Wholohan BT, Zimitat C, Moxon LN et al (1993). Application of high field localised in vivo $1 \mathrm{H}$ MRS to study biochemical changes in the thiamin deficient rat brain under glucose load. NMR Biomed 6: 324-328.

Ross BD, Jacobson S, Villamil F, Korula J, Kreis R, Ernst T et al (1994). Subclinical hepatic encephalopathy: proton MR spectroscopic abnormalities. Radiology 193: 457-463.

Rossetti ZL, Carboni S, Fadda F (1999). Glutamate-induced increase of extracellular glutamate through $\mathrm{N}$-methyl-D-aspartate receptors in ethanol withdrawal. Neuroscience 93: 1135-1140.

Rouach H, Clement M, Orfanelli MT, Janvier B, Nordmann R (1984). Fatty acid composition of rat liver mitochondrial phospholipids during ethanol inhalation. Biochimica Biophys Acta 795: 125-129.

Savage LM, Pitkin SR, Knitowski KM (1999). Rats exposed to acute pyrithiamine-induced thiamine deficiency are more sensitive to the amnestic effects of scopolamine and MK-801: examination of working memory, response selection, and reinforcement contingencies. Behav Brain Res 104: 13-26.

Schweinsburg BC, Alhassoon OM, Taylor MJ, Gonzalez R, Videen JS, Brown GG et al (2003). Effects of alcoholism and gender on brain metabolism. Am J Psychiatry 160: 1180-1183.

Schweinsburg BC, Taylor MJ, Alhassoon OM, Videen JS, Brown GG, Patterson TL et al (2001). Chemical pathology in brain white matter of recently detoxified alcoholics: a $1 \mathrm{H}$ magnetic resonance spectroscopy investigation of alcohol-associated frontal lobe injury. Alcohol Clin Exp Res 25: 924-934.

Seitz D, Widmann U, Seeger U, Nagele T, Klose U, Mann K et al (1999). Localized proton magnetic resonance spectroscopy of the cerebellum in detoxifying alcoholics. Alcohol Clin Exp Res 23: $158-163$

Slawecki CJ (2006). Two-choice reaction time performance in Sprague-Dawley rats exposed to alcohol during adolescence or adulthood. Behav Pharmacol 17: 605-614.

Somogyi JC, Kopp PM, Filippini L, Monnat A (1980). Transketolase-TPP-effect in chronic alcoholics with various degrees of liver cirrhosis. J Nutr Sci Vitaminol 26: 221-229.

Spector R (1976). Thiamine transport in the central nervous system. Am J Physiol 230: 1101-1107.

Srinivasan R, Sailasuta N, Hurd R, Nelson S, Pelletier D (2005). Evidence of elevated glutamate in multiple sclerosis using magnetic resonance spectroscopy at 3 T. Brain 128: 1016-1025.

Stoll AL, Renshaw PF, Demicheli E, Wurtman R, Pillay SS, Cohen BM (1995). Choline ingestion increases the resonance of choline- 
containing compounds in human brain: an in vivo proton magnetic resonance study. Biol Psychiatry 37: 170-174.

Sumida KD, Hill JM, Matveyenko AV (2007). Sex differences in hepatic gluconeogenic capacity after chronic alcohol consumption. Clin Med Res 5: 193-202.

Swain M, Butterworth RF, Blei AT (1992). Ammonia and related amino acids in the pathogenesis of brain edema in acute ischemic liver failure in rats. Hepatology 15: 449-453.

Tabakoff B (1979). Neurotransmitter function and alcoholism. Alcohol Clin Exp Res 3: 351-352.

Tallaksen CM, Bell H, Bohmer T (1992a). The concentration of thiamin and thiamin phosphate esters in patients with alcoholic liver cirrhosis. Alcohol Alcohol 27: 523-530.

Tallaksen CM, Bohmer T, Bell H (1992b). Blood and serum thiamin and thiamin phosphate esters concentrations in patients with alcohol dependence syndrome before and after thiamin treatment. Alcohol Clin Exp Res 16: 320-325.

Tallaksen CM, Bohmer T, Karlsen J, Bell H (1997). Determination of thiamin and its phosphate esters in human blood, plasma, and urine. Methods Enzymol 279: 67-74.

Tedeschi G, Bertolino A, Righini A, Campbell G, Raman R, Duyn $\mathrm{JH}$ et al (1995). Brain regional distribution pattern of metabolite signal intensities in young adults by proton magnetic resonance spectroscopic imaging. Neurology 45: 1384-1391.

Thomson AD (2000). Mechanisms of vitamin deficiency in chronic alcohol misusers and the development of the WernickeKorsakoff syndrome. Alcohol Alcohol Suppl 35: 2-7.

Tsukamoto H, French SW, Benson N, Delgado G, Rao GA, Larkin EC et al (1985). Severe and progressive steatosis and focal necrosis in rat liver induced by continuous intragastric infusion of ethanol and low fat diet. Hepatology 5: 224-232.

Ulrichsen J, Bech B, Ebert B, Diemer NH, Allerup P, Hemmingsen $\mathrm{R}$ (1996). Glutamate and benzodiazepine receptor autoradio- graphy in rat brain after repetition of alcohol dependence. Psychopharmacology 126: 31-41.

Urenjak J, Williams SR, Gadian DG, Noble M (1992). Specific expression of $\mathrm{N}$-acetylaspartate in neurons, oligodendrocytetype- 2 astrocyte progenitors, and immature oligodendrocytes in vitro. J Neurochem 59: 55-61.

Urenjak J, Williams SR, Gadian DG, Noble M (1993). Proton nuclear magnetic resonance spectroscopy unambiguously identifies different neural cell types. J Neurosci 13: 981-989.

Walker JE, Gordon ER (1970). Biochemical aspects associated with an ethanol-induced fatty liver. Biochem J 119: 511-516.

Xia JX, Li J, Zhou R, Zhang XH, Ge YB, Ru Yuan X (2006). Alterations of rat corticostriatal synaptic plasticity after chronic ethanol exposure and withdrawal. Alcohol Clin Exp Res 30: 819-824.

Yin $\mathrm{M}$, Wheeler MD, Kono $\mathrm{H}$, Bradford BU, Gallucci RM, Luster MI et al (1999). Essential role of tumor necrosis factor alpha in alcohol-induced liver injury in mice. Gastroenterology 117: 942-952.

Zahr NM, Mayer D, Pfefferbaum A, Sullivan EV (2008). Low striatal glutamate levels underlie cognitive decline in the elderly: evidence from in vivo molecular spectroscopy. Cereb Cortex [e-pub ahead of print, 29 January 2008].

Zimmermann C, Ferenci P, Pifl C, Yurdaydin C, Ebner J, Lassmann $\mathrm{H}$ et al (1989). Hepatic encephalopathy in thioacetamideinduced acute liver failure in rats: characterization of an improved model and study of amino acid-ergic neurotransmission. Hepatology 9: 594-601.

Zwingmann C, Chatauret N, Rose C, Leibfritz D, Butterworth RF (2004). Selective alterations of brain osmolytes in acute liver failure: protective effect of mild hypothermia. Brain Res 999: $118-123$. 